\title{
Convergence of the Unmanned Aerial Industry
}

\author{
Johnny Elie Chamata \\ Faculty of Business, Curtin University, Malaysia \\ Email: johnny.chamata@gmail.com
}

How to cite this paper: Chamata, J.E. (2017) Convergence of the Unmanned Aerial Industry. Theoretical Economics Letters, 7, 175-186.

https://doi.org/10.4236/tel.2017.72015

Received: January 17, 2017

Accepted: February 24, 2017

Published: February 27, 2017

Copyright $\odot 2017$ by author and Scientific Research Publishing Inc. This work is licensed under the Creative Commons Attribution International License (CC BY 4.0).

http://creativecommons.org/licenses/by/4.0/

\begin{abstract}
Industry convergence-the merger of previously unrelated industries-is a model that has had a strong influence on various industries and received substantial attention among practitioners over the past years. Despite this, industry convergence has received little attention in the field of unmanned aircraft. As the unmanned aircraft industry is still in the infancy stage, exploring the industrial status may contribute to the technology's body of knowledge and may be useful for entrepreneurial decision making. Thus, this research paper investigates the degree to which the unmanned aerial vehicle sector represents an example of industry convergence and predicts the consequences built upon it. The investigation is based on the convergence theory and evidence from the unmanned aerial systems industry is provided to support theoretical foundations. Conclusions show that unmanned aerial technology is converged to an undefined extent and the author calls for further related empirical research.
\end{abstract}

\section{Keywords}

Unmanned Aircraft, Aerial Systems, Industry Convergence, Industrial Analysis, Drivers, Consequences

\section{Introduction}

The modern history of unmanned aircraft (aka drones) goes back to the Great War where some aircrafts were employed in the battlefield [1]. Literature shows though that the history of unmanned aircraft goes back to the Ming Dynasty around 450 B.C., where it was used both for entertainment and in battlefield [2].

The interest in civil unmanned aerial vehicles ${ }^{1}$ (UAV) started in the 1970s, specifically in experiments on flying solar-powered aircraft [1]. Today, civil drones are being employed in hundreds of applications in different sectors. LeMieux (2014) describes three-hundred current applications in telecommunica-

${ }^{1}$ Alternative terms: unmanned aerial systems (UAS), unmanned aircraft, drones. 
tions, agriculture, conservation, disaster management, law enforcement and others [3].

The use of UAS can be of great benefit in many cases. Let us take an example of monitoring high tension towers where usually a helicopter carrying up to six personnel on-board are employed to survey thousands of kilometres [4]. The use of UAVs instead can hugely cut down costs of hiring the helicopter and paying the personnel's wages, and may reduce the risks of injury or maybe life loss.

The UAS industry is able to boost economies through generating hundredthousands of jobs and billions of revenue [5] [6] [7] [8]. In other words, the UAS industry holds the promise of economic salvation for many nations. As a matter of fact, the EU puts big hopes on it in realizing its 2020 economic goals [9]. However, the broad adoption of unmanned aerial technology (UAT) seems to be delayed, which is resulting in huge economic losses [7].

Literature on unmanned aircraft is still developing and several aspects are not yet addressed which might be one of the reasons behind the delay of UAT adoption. For instance, the literature does not discuss theory relevant to the adoption of unmanned aircraft; it merely discusses social acceptance and concerns, as well as regulations. Additionally, very little economic research exists. It is believed that [7], [10] and [11] conclude the economic research conducted. Relatedly, no research has been done on the industrial convergence of unmanned aircraft. Thus, this research paper aims at filling some of the literature gaps by investigating the degree to which the unmanned aerial vehicle sector represents an example of industry convergence and by predicting the consequences of this convergence.

\section{Research Significance and Contribution}

Generally, this research is deemed important for the development and progress of UAS literature. It is novel and believed to be the first research that investigates the convergence of unmanned aerial industry. Such novelty rests its shadows on further development of relevant economic research. For instance, future research may use the analysis provided herein as a basis for a larger investigation [e.g. exploration of further UAS-specific drivers]. Moreover, as this research is crossfertilized with economic [convergence] theory; it may encourage economists to employ or develop theory/models that explain and predict the economic influence of broadly deploying unmanned aircraft.

The research is also timely. The topic on unmanned aircraft is globally arising; thus, it becomes a necessity for research to highlight relevant issues such as the one presented here, or other ones such as economic potentials and benefits, feasibility of deploying UAS technology, ... etc. Neglection of such timeliness may undermine the potentials of both the research on unmanned aircraft and progress of the technology.

On the other hand, the research has practical contributions. The industrial analysis conducted herewith may further the knowledge of entrepreneurs and policymakers interested in the industry's status; which may encourage invest- 
ments or the implementation of more flexible policies; that would accelerate the progress of the UAS industry. By benchmarking with the contribution of IT convergence research [consulted herein] to the progress of its industry, similar outcomes are expected. Additionally, managers currently engaged in unmanned aircraft business operations may benefit by learning about drivers of convergence as well as consequences ahead, as it provides them with deep insights necessary for future business plans.

\section{UAS Industry Analysis}

In this section, the author relies on Porter's Five Forces Model [12] [13] to identify and discuss factors that define the UAS industrial status. This acts as a preliminary evaluation necessary for answering some of the aspects of the question on the convergence of unmanned aerial industry. Additionally, the section includes forecasts of UAS profitability [7] [9] complementary to the industrial analysis.

\subsection{Porter's Five Forces}

1) Competition from substitutes

Unmanned aircraft are unique in their capabilities and hence in the value they provide. These systems can fly anywhere and over places no other systems can reach. These capabilities allow them to be useful in hundreds of applications such as providing medical assistance [14] and Internet services in isolated area, search and rescue, as well as monitoring infrastructures and establishments [3], [15]. Moreover, unmanned aircraft provide economic value; for they are cheaper and easier to learn compared to their substitutes [e.g. helicopters], unmanned aircraft can cut down operational and overhead costs tremendously [4]. Other noteworthy benefits concern time saving capabilities; imagine someone is having a stroke, and count the time needed for both traditional and ambulance drones to reach for rescue. With these values explained, we can confidently claim that competition from substitutes should be very low.

2) Rivalry between established competitors

A world's UAS production map clearly shows an unbalance in profitability across continents. In 2009, North America alone generated profits of $\$ 2.7$ billion followed by Europe with $\$ 780$ million while the rest of the world barely made $\$ 280$ million [2]. Additionally, Chamata (2016a) argues there is an unbalance in the number of manufacturers worldwide. He shows industrial evidence that the number of manufacturers is overruled by the EU, Asia-Pacific and North America (Figure 1); while South America (i.e. 21 producers) and Africa (i.e. 6 producers) are way lagging behind [16].

Thus, we conclude a few points herein: first, there is a low level of rivalry worldwide; however, with the absence of sufficient information, we cannot confirm the level of rivalry per country. It is believed there is no literature that discusses the factors yielding the low UAS industrial rivalry; however, Chamata (2016b) has discussed several socio-economic factors which may give a feeling 


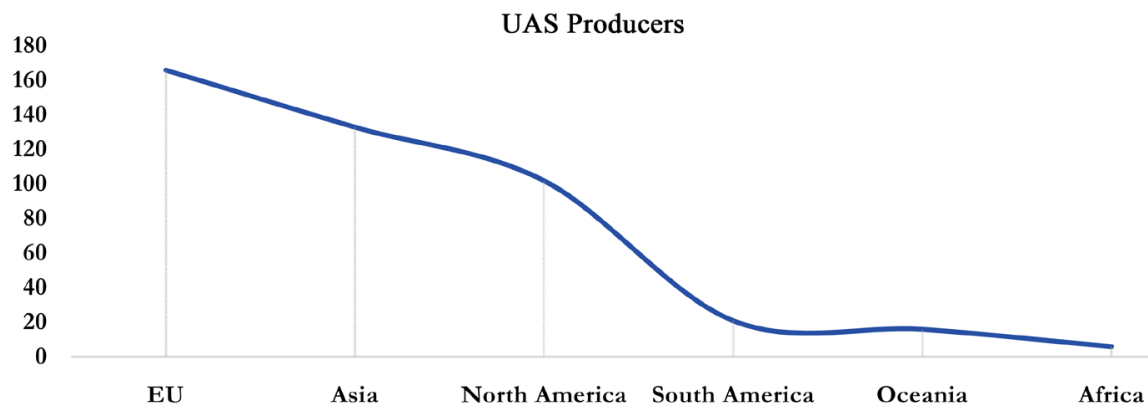

Figure 1. UAS Producers Worldwide-Adapted from UAV Global (2016)—Credit: Author.

[17]. Second, a contradiction between the profitability levels and the number of manufacturers proves that they are not necessarily related. Therefore, it would be relevant to first seek means of increasing demand rather than increasing rivalry. Chamata and Winterton (forthcoming) propose factors that may increase consumers' motivation to use unmanned aircraft [18]. But remains a question, do we need to restructure the UAS industry to balance competition? However, this is beyond the scope of this paper, thus is left for future research to investigate.

3) Bargaining power of buyers \& suppliers

Based on the above, we may presume that bargaining power will vary per assessment criteria: if we are looking at a cross-continental and cross-country level then buyers' bargaining powers exist. For instance, a user who resides in Europe may easily turn over to an Asian manufacturer for less expensive products; or a user who lives in Belgium may seek reliable German products. On the other hand, within the same country, suppliers' bargaining power would rule because of price competition, however, this assumes a small number of manufacturers within the country. For instance, this is considered invalid in a country such as the United States which has a very large number of manufacturers [19].

4) Entry barriers

One may easily be deceived with the above analysis, and conclude that entry barriers to the UAS industry are low. Nonetheless, this may not be the case! Recent research on the adoption of civil drones has proposed several factors as barriers against the investment in unmanned aircraft. Due to the several issues associated with UAS technology, the research proposes, several societal concerns are leading to lawful actions towards the technology [e.g. bans, delayed regulations], which in addition to investors' fear of job replacement and skill destruction, are demotivating investment in unmanned aircraft, thus delaying its adoption on organizational [and maybe individual] level [17]. We therefore interpret that competition alone cannot determine the entry barriers' level to the UAS industry, but also additional social determinants. Thus, we consider that entry barriers to the UAS industry are high due to exogenous factors.

\subsection{Forecasting Profitability}

Forecasting profitability is complementary to industrial analysis as it provides a 
feeling of anticipated profits necessary for existing and future investors or rivals. Nonetheless, whereas conducting an analysis of economic potentials is not in the scope of this research, we rely on existing reports to give a general feeling (Figure 2).

Industrial reports show an increasing drone sales movement. Forbes (2015), the prominent economic magazine, reports that over a period of one year, suppliers' sales have increased from less than 1000 aircraft/month in the beginning of the year to almost 9000 aircraft/month towards the its end [20]. Another report shows that, regardless the volume, the sales of three prominent companies consistently increased between years 2013 and 2015 [21].

On the other hand, forecasts show that the EU will have a trading movement of unmanned aircraft worth $€ 15$ billion per year and create up to 150,000 manufacturing jobs by 2050 [9]. In the United States, annual revenues would hit $\$ 13.6$ billion along with the creation of 70,000 jobs [7]. It strikes the eyes to observe that the EU report's focus is on manufacturing jobs specifically, which implies

\section{WEEKLY SALES IN UNITS}

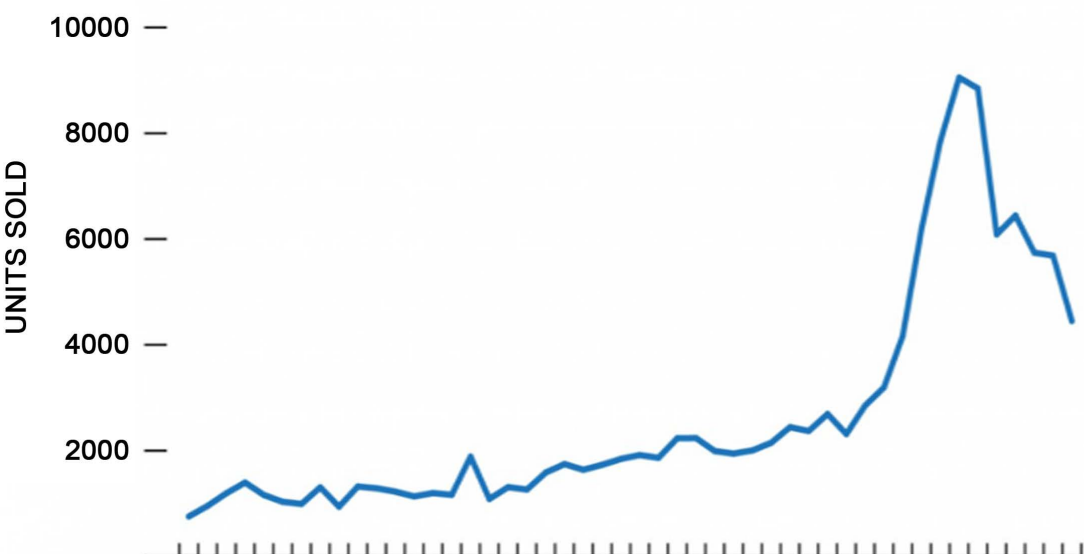

Feb 28 Apr 11 May 23 Jul 4 Aug 15 Sep 26 Nov 7 Dec 19 Jan 23

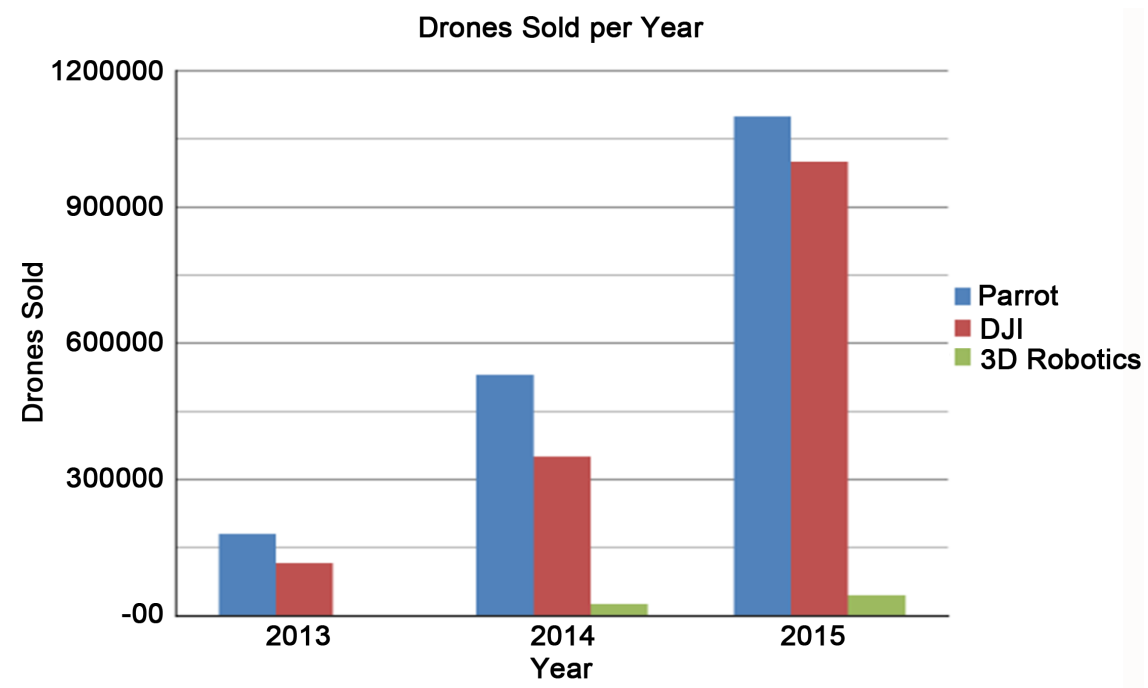

Figure 2. Drone sales reported on different sources (Forbes, 2015; Drone Life, 2015). 
either that there is more need for manufacturing staff or that the ambition and expectations of the UAS industry leaders are too high. In both cases, caution is recommended in forecasts because of the importance of decisions based upon them.

\section{Is the UAS Industry Converged Yet?}

This section answers the key research question: is the UAS industry converged? To provide an answer, a brief overview of the elements necessary for convergence is provided then benchmarked with current insights on the industry status. Moreover, the section predicts consequences of the UAS industry convergence realising few [consequences] are already taking place.

\subsection{Overview of Convergence Theory}

The definition of industry is clearly dominated by the concept of industry convergence and is essential for defining industrial boundaries [22]. Andrews (1951) defines an industry as "any grouping of individual ... businesses which is relevant when we study the behaviour of any one such business" (p. 12). He farther considers convergence as a main characteristic of an industry when he articulates that all businesses employ similar technical processes and possess similar knowledge and experiences which may be extended to merging firms which are different on both technical and resource levels [23].

In line with that, Bain (1968) defines convergence as a group of organizations which deliver products and services that are substitutes and which target a common cluster of customers [24]. Recent literature prefers to define convergence as a "blurring" of boundaries between industries [25] which leads to the redefinition of these boundaries [22] and consequently to the creation of a new inter-industry business sector [25].

Industrial convergence is concerned with the degree to which industries meet or intersect to produce "hybrid" products or services. The process consists of several phases of merger including inclination, meeting, developing, moving, and fully merging. Thus, it is clear that industrial convergence is a dynamic process [26]. This dynamic process, explained in more detail by Weaver (2007), results in different outcomes. It may result in the emergence of a novel and fully merged industry with definable boundaries. A semi-merged industry is another possibility, in which both industries overlap whereas one acts as a sub-segment of the other. Convergence may also cause the creation of a delitescent state of merger, where boundaries are continually changing [22].

The first instance of "convergence" applied to industries was by Nathan Rosenberg in 1963. In his article "Technological change in the machine tool industry, 1840-1910", he referred to technological convergence. He noted that different products such as firearms, sewing machines and bicycles, are produced using the same technology and even machinery. Nathan Rosenberg concluded that certain products, which may be unrelated by nature or use, are actually very closely related from a technological point of view [27]. Thus, different processes 
normally used by different sectors at different stages of production, can now be used to develop different products [or services] [26].

\subsection{Drivers of Convergence}

Different factors are responsible of directing an industry towards convergence. While the literature is rich in describing drivers in various sectors, it is observed they are broadly categorised into exogenous and endogenous factors. Exogenous factors relate to unpredictable environmental and technological changes, whereas endogenous ones are somehow foreseeable and rely on corporate leaders' decision-making.

\subsubsection{Exogenous Elements}

Environmental considerations such as economic need and increased or decreased competition induce the need for a particular industry to survive and uphold its competitiveness [28]. An instance of economic need was evident during the start of the economic crisis in 2008, when the EU experienced numerous mergers in the finance sector (government-private, private-private) aiming to rescue banks at risk of failure [29]. The influence of rivalry is clear in how the telecommunication industry evolved over the past two decades. When traditional telephony systems (i.e. PSTN) were becoming obsolete for both households and organizations, IP telephony systems emerged for many reasons among which were productivity, efficiency [30], cost effectiveness and flexibility [31].

Technological drivers are the result of either scarcity of certain products [i.e. technological need] which motivate an industry to search for alternatives; or the readiness of integrative platforms that allow merging different products into a new hybrid output. For example, because of petroleum scarcity, there is an inclination in the United States to merge green chemistry with biotechnology for the sake of synthesizing aromatic products from bio-based chemicals instead of materials derived from benzene, toluene or xylene [28]. A prominent model of integrative platforms is the Internet [32]. It is notable how several technologies appeared after the rise of the Internet and which mostly use it as a platform (e.g. blogs, wikis, social networks, instant messaging) [33].

\subsubsection{Endogenous Elements}

Obviously, industrial convergence is also an outcome of decision-making process at the firm level. Managers pursuing new business opportunities often rely on innovative ideas which may require the merger with another firm from a different industry [22]. For instance, the late Steve Jobs revolutionized the mobile phone technology as he merged it with computer technology, thus resulting in the introduction of smart phone technology. Examples of smart products he introduced are the iPhone and iPad [34]. The choice of a market strategy is another factor that influences industrial convergence. Corporate leaders willing to enter a new market may for example adopt diversification as a strategy [35]. A famous instance is the Finnish telecom industry converging IT and telecom industries [22]. 


\subsection{Evidence of Convergence}

The history of unmanned aircraft can be traced to World War I [1] but its industrial development is rather neglected in literature. However, the author through a review of the economic research on drones and the examination of current industrial status; could draw conclusions concerning the convergence of the UAS industry.

Existence of economic need: Economic advancement and the creation of more jobs are common aspirations for nations. One example of economic need, is the EU which aims at a $75 \%$ overall employment rate by 2020 [36]. Literature claims the UAS industry is able to contribute to these economic objectives [37], through promoting entrepreneurship, introducing new businesses [8] and creating job opportunities [5]. Moreover, previous reports, as shown above, show potentials of profitability and job creation [see Section 2.2].

Lack of global industrial rivalry. Section 2.1 provides evidence of low and unbalanced rivalry.

Technological Necessity: The emerging number of applications alone is indicative of the technological need for unmanned aircraft. Aside from use in military contexts to reduce casualties and deaths of military personnel, an increasing number of applications is apparent from the extant literature. LeMieux (2013) non-exclusively describes thirty applications for engineering, agriculture, transport and other purposes [15]. Later on, LeMieux (2014) showed that there are currently 300 drone applications in a large variety of industries [3].

$U A S$ as integrative platforms: an unmanned aerial system is by nature an integrative platform for different technologies. Observing the system as described by Barnhart et al. (2011) [38], it is obvious that it requires the merge of different industries to build an advanced unmanned aerial system. In addition to the development of the aircraft as a mechanical procedure, the complete system contains command and control (relies on computer software), communication (relies on GPS and/or WiFi) and payload (e.g. cameras, sensors) elements.

Managerial Innovation: It is evident that the design of smarter drones in recent years reflects innovative behaviours of organizations. For instance, organizations in 2015 began to develop drones that autonomously follow the person as they move, ski, hike or do whatever activity. Examples are the Lily, Hexo+ and Solo smart drones [39] [40] [41]. Most recently, a diversification strategy was evident in the creation of supersized drones (aka flying cars) capable of carrying passengers. A prominent instance is the Ehang184 equipped with a fail-safe system and powered by electricity [42].

Based on the above, we may conclude then that the unmanned aerial industry is converged and has all the elements of convergence satisfied. Next, remains one objective; that is predicting the consequences of this convergence, presented in the following section.

\subsection{Consequences of Convergence}

Any industry which undergoes convergence experiences effects on both industry 
and firm levels. From an industry perspective, convergence (of the unmanned aerial industry) is anticipated to result in market growth represented in elevated competition and rivalry [43] observed in an increase in the number of UAV manufacturers and traders [17]. Relatedly, strategic alliances are more likely to develop further, such as the current partnership between NASA, Google and 13 other firms to design an unmanned aerial system (UAS) traffic management system. Along with 100 businesses and academic institutions, they have signed an agreement for the execution of the project [44]. The UAS industry is also expected to restructure its value chain depending on the manufactured product. Different products may require altering or removing manufacturing processes (e.g. the case of smart and supersized drones) hence influencing the added-value of the unmanned aircraft. In addition, the regulators [of unmanned aircraft] will more likely be obliged to implement more relaxed flight rules and restrictions [45] as is the current situation in Canada, Australia and most recently the United States.

Industry convergence is a dynamic process as concluded earlier, and dynamism by definition implies the absence of a static state. New and existing UAS firms are expected to encounter high uncertainty, resulting in business risks such as the decision to invest or choose a business strategy [22]. However, to reduce business risks, firms are advised to cooperate in research [25] and to network with producers to create value that may outweigh risks [22]. Another consequence concerns the firms' resources. There are threats that technological change associated with industry convergence may lead to the destruction of staff competencies. In such case, organizations are recommended to implement relevant human resources strategies, raising flexibility through deploying staff skills in ways appropriate to the altered situation [22].

\section{Conclusion}

This paper has discussed and examined the convergence of the UAS industry based on literature on strategic management and theory of convergence. Conclusions show that the UAS industry is converged on different economic, technological, and managerial levels. The convergence of unmanned aircraft industry is expected to have consequences on both macro and micro economics levels, from increased rivalry and establishment of alliances to elevated business risks and threats concerning labour.

\section{Research Limitations and Future Research Directions}

Like is the case for most industry convergence research, this research lacks empirical analysis. It is important that future research works on empirical evidence as it is essential for validating research conclusions and providing more reliable results. This research also, meant to be brief, has not broadly discussed the convergence theory found essential in laying the grounds for future research. A broad discussion may provide deeper insights on understanding the research topic and interpreting results. Finally, the conclusions presented herewith are 
limited to the influence of industrial and technical factors. In the future, the inclusion of socio-political factors may enrich research and provide a different perspective of the UAS industry convergence.

\section{Acknowledgements}

This research is funded by the Graduate School at Curtin University, Malaysia. The author would like to also acknowledge the constructive feedback of the anonymous reviewer, as well as the assistance of Ms. Deng Jing from the journal's editorial office.

\section{References}

[1] Valavanis, K.P. and Vachtsevanos, G.J. (2015) Handbook of Unmanned Aerial Vehicles. Springer Science + Business Media, Dordrecht, 1-3022.

[2] Dalamagkidis, K., Valavanis, K. and Piegl, L.A. (2012) On Integrating Unmanned Aircraft Systems into the National Airspace System. 2nd Edition, Springerlink + Business Media, Dordrecht.

[3] LeMieux, J. (2014) Drone: UAV Dictionary. Unmanned Vehicle University, Phoenix.

[4] Sebbane, Y.B. (2012) Lighter than Air Robots. Springer Science + Business Media, Dordrecht.

[5] Gibbens, D. (2014) Editorial Integrating UAS into the Oil and Gas Industry.

[6] Guiraud, M. and Nachescu, M.-L. (2012) Drones as a Tool of Sustainable Development-Consequences of Their Usage and New Forms of Risk Management. Economic and Environmental Studies, 12, 467-479.

[7] Jenkins, D. and Vasigh, B. (2013) The Economic Impact of Unmanned Aircraft Systems Integration in the United States. 1-40.

[8] Volovelsky, U. (2014) Civilian Uses of Unmanned Aerial Vehicles and the Threat to the Right to Privacy-An Israeli Case Study. Computer Law \& Security Review, 30, 306-320.

[9] EU Business (2014) Remotely Piloted Aviation Systems, or Drones. http://www.eubusiness.com/topics/transport/drones/?searchterm=droneeconomy

[10] Camilli, L. (2015) Emerging Technologies, Applications, Regulations, and Market Challenges in the Consumer Aerial Drone Industry: A Strategic Analysis of the 3D Robotics Business Model. San Francisco.

[11] Olejnicek, A. (2012) Economic Aspects of the Military Robotics Introduction and Development in the War Theatre. In: Eslamian, S., Ed., Recent Advances in Energy, Environment and Economic Development, WSEAS Press, 368-373.

[12] Moreno-Izquierdo, L., Ramon-Rodriguez, A.B. and Perles-Ribes, J.F. (2016) Pricing Strategies of the European Low-Cost Carriers Explained Using Porter's Five Forces Model. Tourism Economics, 22, 293-310.

[13] Porter, M.E. (2008) The Five Competitive Forces That Shape Strategy. Harward Business Review, 86, 79-93.

[14] CNET (2014) Ambulance Drone Delivers Help to Heart Attack Victims. https://www.cnet.com/news/ambulance-drone-delivers-help-to-heart-attack-victim s/

[15] LeMieux, J. (2013) Drones and UAV Entrepreneurship: 30 Businesses You Can Start. Unmanned Vehicle University, Phoenix. 
[16] Chamata, J.E. (2016) Industry Convergence: The Case of Unmanned Aerial Systems. 1-5.

[17] Chamata, J.E. (2016) On the Adoption of Civil Drones: A Note for Entrepreneurs and Policy Makers. Proceedings of the 4th Global Conference on Business and Social Sciences on Contemporary Issues in Business and Social Sciences Research: A Dubai Initiative, Dubai, 14 November 2016, 218.

[18] Chamata, J. and Winterton, J. Factors Influencing the Acceptance of Unmanned Aerial Systems : Exploratory Research. 1-22.

[19] Global, U. (2016) List of All Manufacturers. http://www.uavglobal.com/list-of-manufacturers/

[20] Forbes (2015) Drone Sales Soar Past \$16 Million on eBay. http://www.forbes.com/sites/frankbi/2015/01/28/drone-sales-soar-past-16-million-o n-ebay/\#41a375924e6e

[21] Drone Life (2015) Drone Sales Numbers: Nobody Knows, So We Venture a Guess. http://dronelife.com/2015/04/16/drone-sales-numbers-nobody-knows-so-we-ventu re-a-guess/

[22] Weaver, B. (2007) Industry Convergence: Driving Forces, Factors and Consequences. 19th NFF Conference, Bergen, 9-11 August 2007, 9-11.

[23] Nightingale, J. (1978) On the Definition of Industry and Market. Vol. XXVII, No. i.

[24] Bain, J.S. (1968) Industrial Organization. John Wiley \& Sons, Hoboken.

[25] Rosenberg, N. (1963) Technological Change in the Machine Tool Industry, 18401910. The Journal of Economic History, 23, 414-443.

[26] Bröring, S., Cloutier, M.L. and Leker, J. (2006) The Front End of Innovation in an Era of Industry Convergence: Evidence from Nutraceuticals and Functional Foods. R\& D Management, 36, 487-498.

[27] Curran, C.S. (2013) The Anticipation of Converging Industries: A Concept Applied to Nutraceuticals and Functional Foods.

[28] Philp, J.C., Ritchie, R.J. and Allan, J.E.M. (2013) Biobased Chemicals: The Convergence of Green Chemistry with Industrial Biotechnology. Trends in Biotechnology, 31, 219-222.

[29] Weitbrecht, A. (2010) Mergers in an Economic Crisis-EU Merger Control 2008/ 2009. European Competition Law Review, 31, 276-284.

[30] Cisco (2002) Cisco Undertakes the Largest IP Telephony Deployment in Industry History.

[31] Kim, K. and Wang, C. (2011) Enterprise VoIP in Fixed Mobile Converged Networks. Studies in Computational Intelligence, 346, 585-621.

[32] Lei, D.T. (2000) Industry Evolution and Competence Development: The Imperatives of Technological Convergence. International Journal of Technology Management, 19, 699-738.

[33] Walsh, K. (2009) 10 Internet Technologies That Educators Should Be Informed about.

http://www.emergingedtech.com/2009/04/10-internet-technologies-that-educatorsshould-be-informed-about/

[34] Apple Homepage (2016). http://www.apple.com

[35] Pennings, J.M. and Puranam, P. (2000) Market Convergence \& Firm Strategies: Towards a Systematic Analysis.

[36] EU Commission (2011) Europe 2020 Targets.

http://ec.europa.eu/europe2020/targets/eu-targets/index_en.htm 
[37] Wallace, L., Musk, R. and Lucieer, A. (2014) An Assessment of the Repeatability of Automatic Forest Inventory Metrics Derived from UAV-Borne Laser Scanning Data. IEEE Transactions on Geoscience and Remote Sensing, 52, 7160-7169.

[38] Barnhart, R.K. (2011) 12 the Future of Unmanned Aircraft Systems. In: Marshall, D.M., Barnhart, R.K., Hottman, S.B., Shappee, E. and Most, M.T., Eds., Introduction to Unmanned Aircraft Systems, CRC Press, Boca Raton, 181.

[39] Lily (2016) Lily Homepage. http://www.lily.camera

[40] Hexo + (2016) Hexo + Homepage. https://hexoplus.com/

[41] 3DR (2016) 3DR Homepage. https://3dr.com/solo-drone/

[42] Ehang (2016) Ehang184 Homepage. http://www.ehang.com/ehang184

[43] Hacklin, F. (2008) Management of Convergence in Innovation: Strategies and Capabilities for Value Creation beyond Blurring Industry Boundaries.

[44] Russia Today (2015) Google, NASA Work Together to Design Drone Air-TrafficControl System. https://www.rt.com/usa/310705-drone-air-traffic-control/

[45] Tardiff, T.J. (2007) Changes in Industry Structure and Technological Convergence: Implications for Competition Policy and Regulation in Telecommunications. International Economics and Economic Policy, 4, 109-133.

Submit or recommend next manuscript to SCIRP and we will provide best service for you:

Accepting pre-submission inquiries through Email, Facebook, LinkedIn, Twitter, etc. A wide selection of journals (inclusive of 9 subjects, more than 200 journals)

Providing 24-hour high-quality service

User-friendly online submission system

Fair and swift peer-review system

Efficient typesetting and proofreading procedure

Display of the result of downloads and visits, as well as the number of cited articles

Maximum dissemination of your research work

Submit your manuscript at: http://papersubmission.scirp.org/

Or contact tel@scirp.org 